\title{
Implementation of FACTS Device for Enhancement of ATC Using PTDF
}

\author{
${ }^{1}$ Ibraheem and ${ }^{2}$ Naresh Kumar Yadav
}

\begin{abstract}
In this paper an attempt has been made to determine Available Transfer Capability (ATC) with the FACTS device i.e. TCSC. The methods for ATC evaluation are developed considering system thermal limits constraints based on MVA loading of the system. Power Transfer Distribution Factors (PTDF) are used to determine the maximum ATC that may be available across the system in a certain direction without violating line thermal limits. ATC traditionally uses linear methods capable of predicting distances based on thermal limits. However, these methods do not consider bus voltages and static collapse. Most of the studies relating ATC involve contingencies and multi-pattern scenarios that often can only be performed in reasonable time with the use of linear methods. In this paper, a new approach is proposed that first determines the Reactive Power Flows using the exact circle equation for the transmission line complex flow, and then evaluates ATC using active power distribution factors. The effectiveness of proposed method is successfully demonstrated on IEEE 30-Bus system.
\end{abstract}

Index Terms-ATC, PTDF, TCSC, Reactive Power.

\section{INTRODUCTION}

Available Transfer Capability (ATC) is a measure of the ability of interconnected electric power system to reliably move or transfer power from one area to another, over the transmission system between the given areas, under specified system conditions. It is useful in making power transaction contracts in the system, operating a power system within its ATC limits ensures that the system will continue to supply electric power on demand, even under certain abnormal conditions[1]. This ATC information can be used for the commercial marketing of electricity, i.e. the ATC information is useful for deciding the new power transaction reservations between the market participants. The ATC is calculated and provided by Independent System Operator (ISO) to indicate the system capability for further power transactions. Then the customer decides and reserves the transmission delivery services like amount of power to be transacted, the transmission path, the time period of reservation and ancillary services ATC $=$ TTC - TRM Existing Transmission Commitments (including CBM) [2].

The methods reported in the literature for static ATC determination can be broadly classified as Repeated Power Flow (RPF) and Continuation Power Flow (CPF) based methods [3-5], Sensitivity based methods [6-8] and Optimal

Manuscript received October 8, 2010; revised February 19, 2011.

Ibraheem is with the Department of Electrical Engineering, at Jamia Millia Islamia (Central University), New Delhi (E-mail: ibraheem_2k@yahoo.com).

Naresh Kumar Yadav is with the Department of Electrical Engineering, at Deenbandhu Chhotu Ram University of Science and Technology, Sonepat (E-mail: nkyadav76@gmail.com).
Power Flow (OPF) based methods [9-11]. Some theoretical aspects of ATC and the problem of its evaluation under open access environment have been discussed in [12]. Some of the technical challenges of computing transfer capability in electric power systems have been discussed in [13]. A novel formulation of ATC problem based on full AC power flow solution to incorporate the effects of reactive power flows, voltage limits as well as voltage stability and line flow limits has been reported in [1]. AC Power Transfer Distribution Factors(ACPTDFs) and Voltage Distribution Factors (VDFS) for the fast determination of ATC using thermal limits and voltage limits has been proposed in the literature[8].

Flexible AC Transmission systems (FACTs) controllers are power electronic based compensating devices and are known for their ability to improve power system stability and enhancing the system power transfer capability [14]. A methodology, based on stochastic programming to enhance ATC of prescribed interfaces in an interconnected power system utilizing Unified Power flow Controller (UPFC), has been presented in [15]. An OPF based ATC enhancement model to achieve the maximum power transfer between the specified interfaces with FACTS controllers such as Thyristor Controlled Phase Shifter (TCPS), SVC, TCSC, and UPFC has been investigated in [15]. Moreover, an eigen vector analysis for optimizing the location, Sizing and Control modes of SVC and TCSC in order to achieve the maximum load-ability has also been reported in literature [16]. A hybrid heuristic approach, combining the Real Genetic Algorithm (RGA) associated with Analytical Hierarchy Process (AHP) and fuzzy sets, has been proposed to determine the optimal location of TCSC in [17] for ATC enhancement and standard voltage collapse technique to determine the ATC has been proposed in [18]. The additional detailed information can be obtained regarding ATC computation in ref. [19-22].

\section{ATC PROBLEM FORMULATION}

\section{A. Linear Static Method}

Linear ATC typically assumes a lossless system, where changes in real power flow is linearly related to changes in power injections. For illustration, we assume a transfer from the slack bus, to any bus, and maximize this transfer without exceeding any line or transformer. The key to the linear power solution is the use of "Power Transfer Distribution Factors (PTDF)" expressed here as sensitivities of line real power injections [1].

These PTDFs are essentially current dividers in linear circuit theory. As such, they are large-change sensitivities and can be used to predict the change in the line flow (line 
$i-j$ ) due to a transfer bus $\left({ }^{s}\right)$ to bus $(b)$ as:-

$$
\begin{gathered}
\rho_{i j, T}=\frac{\partial P_{i j}}{\partial P} \\
\rho_{i j, T}=-\frac{\partial P_{i j}}{\partial P} \\
\Delta P_{i j}=\rho_{i j \rightarrow T} \Delta P_{s}=-\rho_{i j} \Delta P_{K}
\end{gathered}
$$

Note that $\Delta P_{s}=-\Delta P_{k}$ is the amount of transferred power from slack to any other bus. For a given positive line flow limit $P_{i j}^{\max }$, assumed equal to the line MVA rating, and an initial positive line flow $P_{i j}^{0}$ the size of the transfer that drives the line to its limit is equal to:-

$$
\begin{array}{r}
\Delta \mathrm{P}_{\mathrm{s}}^{\mathrm{ij}}=\frac{\mathrm{P}_{\mathrm{ij}}^{\max }-\mathrm{P}_{\mathrm{ij}}^{0}}{\rho_{\mathrm{ij}, \mathrm{i} \rightarrow \mathrm{b}}}, \rho_{\mathrm{ij}, \mathrm{i} \rightarrow \mathrm{b}}>0 \\
\Delta \mathrm{P}_{\mathrm{s}}^{\mathrm{ij}}=\frac{-\mathrm{P}_{\mathrm{ij}}^{\max }-\mathrm{P}_{\mathrm{ij}}^{0}}{\rho_{\mathrm{ij}, \mathrm{i} \rightarrow \mathrm{b}}}, \rho_{\mathrm{ij}, \mathrm{i} \rightarrow \mathrm{b}}<0
\end{array}
$$

In order to determine ATC, the minimum value of $\Delta P_{s}^{i j}$ among all lines in the system is determined [1].

$$
\operatorname{ATC}_{\mathrm{s} \rightarrow \mathrm{b}}=\min \left\{\Delta \mathrm{P}_{\mathrm{s}}^{\mathrm{ij}} \text { for all lines }(\mathrm{i}-\mathrm{j})\right\}
$$

Note that it is the linear relation between the transfer and the line flows that make linear ATC the fastest algorithm for transfer studies to describe the impact of neglecting reactive power flows [1].

\section{B. Reactive Method}

Since the transmission line complex flow is constrained to be on the operating circle and inside the limiting circle, the maximum complex flow of the line $i-j$ corresponds to point $\left(P_{i j}^{*}, Q_{i j}^{*}\right)$. Depending on the sign of the distribution factor two different solutions for $P_{i j}^{*}$ can be found. In order to compute $P_{i j}^{*}$ and $Q_{i j}^{*}$ the following system of equations must be solved:-

We have

$$
P_{i j}^{2}+Q_{i j}^{2}=\left(S_{i j}^{\max }\right)^{2}
$$

After incorporating various equations, we get following operating circle equation:-

$$
\left(P_{i j}-P_{i j e}\right)^{2}+\left(Q_{i j}-Q_{i j e}\right)^{2}=S_{i j e}^{2}
$$

Expanding Eqn. (8) and then subtract Eqn. (7), bringing $Q_{i j}$ to L.H.S so we obtain

$$
\begin{aligned}
& \mathrm{Q}_{\mathrm{ij}}=\left(\frac{1}{2} \mathrm{Q}_{\mathrm{ije}}\right)\left(-2 \mathrm{P}_{\mathrm{ij}} \mathrm{P}_{\mathrm{ije}}+\left(S_{\mathrm{ij}}^{\mathrm{max}}\right)^{2}-\left(\mathrm{S}_{\mathrm{ije}}^{2}-\mathrm{P}_{\mathrm{ije}}^{2}-\right.\right. \\
& \text { Qije2 }
\end{aligned}
$$

Let us assume

$$
\mathrm{S}_{\mathrm{ije}}^{2}-\mathrm{P}_{\mathrm{ije}}^{2}-\mathrm{Q}_{\mathrm{ije}}^{2}=\mathrm{M}^{2}
$$

Substituting Eqn. (10) in Eqn. (9)

$$
Q_{i j}=\left(\frac{1}{2} Q_{i j e}\right)\left(-2 P_{i j} P_{i j e}+\left(S_{i j}^{\max }\right)^{2}-M^{2}\right.
$$

Substituting Eqn. (11) in Eqn. (7) and replace $P_{i j}$ as $P_{i j}^{*}$, we obtain the quadratic expression in $P_{i j}^{*}$ is obtained as:-

$$
\begin{aligned}
& P_{i j}^{* 2}\left(P_{i j b \Theta}^{2}+Q_{i j \Theta}^{2}\right)-P_{i j}^{*}\left[\left(\left(S_{i j}^{\max }\right)^{2}-M^{2}\right) P_{i j \Theta}\right]+ \\
& \left.\left(\frac{1}{4}\right)\left(S_{i j}^{\max }\right)^{2}-M^{2}\right)^{2}-Q_{i j \Theta}^{2}\left(S_{i j}^{\max }\right)^{2}=0
\end{aligned}
$$

Defining the corresponding constant coefficients:-

$$
\begin{gathered}
a=\left(P_{i j \Theta}^{2}+Q_{i j \Theta}^{2}\right) \\
b=-P_{i j \Theta}\left(\left(S_{i j}^{\max }\right)^{2}-M^{2}\right) \\
c=\frac{1}{4}\left(\left(S_{i j}^{\max }\right)^{2}-M^{2}\right)^{2}-Q_{i j \Theta}^{2}\left(S_{i j}^{\max }\right)^{2}
\end{gathered}
$$

Then the solution for the maximum complex flow is obtained as:-

$$
\begin{aligned}
& \mathrm{P}_{\mathrm{ij}}^{*}=\frac{-\mathrm{b} \pm \sqrt{\mathrm{b}^{2}-4 \mathrm{ac}}}{2 \mathrm{a}} \\
& \mathrm{Q}_{\mathrm{ij}}^{*}=\sqrt{\left(\mathrm{S}_{\mathrm{ij}}^{\mathrm{max}}\right)^{2}+\mathrm{P}_{\mathrm{ij}}^{* 2}}
\end{aligned}
$$

The sign in the previous equation is chosen to be positive if the PTDF of line $i-j$ is positive and negative otherwise [1].

$$
\begin{aligned}
\Delta \mathrm{P}_{\mathrm{S}}^{\mathrm{ij}}=\frac{\mathrm{P}_{\mathrm{ij}}^{*}-\mathrm{P}_{\mathrm{ij}}^{0}}{\rho_{\mathrm{ij}, \mathrm{i} \rightarrow \mathrm{b}}}, & \rho_{\mathrm{ij}, \mathrm{i} \rightarrow \mathrm{b}}>0 \\
\Delta \mathrm{P}_{\mathrm{s}}^{\mathrm{ij}}=\frac{-\mathrm{P}_{\mathrm{ij}}^{\mathrm{X}}-\mathrm{P}_{\mathrm{ij}}^{0}}{\rho_{\mathrm{ij}, \mathrm{i} \rightarrow \mathrm{b}}}, & \rho_{\mathrm{ij}, \mathrm{i} \rightarrow \mathrm{b}}<0
\end{aligned}
$$

Steps for Reactive Method

The process of computing linear ATC including the effect of reactive flows is summarized as follows:-

(i) Compute distribution factors $\rho_{i j, T}$;

(ii) Compute $P_{i j}^{*}$ using Eqn. (13) and Eqn. (14a);

(iii) Compute the necessary transfer $\Delta P_{s}^{i j}$ using Eqn. (15) or (16);

(iv) Obtain the minimum $\Delta P_{s}^{i j}$ among all line ends. Since the incorporation of reactive flows into the algorithm resides in computing a new line flow limit, all of the advantages of the linear ATC method are preserved [1].

Therefore, the basic ATC problem regarding thermal security limits is given by an initial operating state of the power system, determine the maximum amount $\Delta P$ for a transaction between seller $(s)$ and buyer $(b)$ such that $\left|S_{i j}\right|<\left|S_{i j}^{\max }\right|$ for all $i-j$ lines in the system [21].

\section{POWER TRANSFER DISTRIBUTION FACTORS}

The Linearized Power Transfer Distribution Factors for a line with respect to a transfer $p T$, where $p$ is the size of 
the transfer in per unit, and $T$ is a vector of participation factors of $\operatorname{size}^{n}$, where $n$ is number of buses that can be calculated using the following equation:-

$$
\begin{array}{r}
\mathrm{T}=\mathrm{T}_{\mathrm{s}}+\mathrm{T}_{\mathrm{b}}=\left[\begin{array}{c}
\mathrm{PF}_{\mathrm{s} 1} \\
\mathrm{PF}_{\mathrm{s} 2} \\
\cdot \\
\cdot \\
\cdot \\
\mathrm{PF}_{\mathrm{sn}}
\end{array}\right]+\left[\begin{array}{c}
\mathrm{PF}_{\mathrm{b} 1} \\
\mathrm{PF}_{\mathrm{b} 2} \\
\cdot \\
\cdot \\
\mathrm{PF}_{\mathrm{bn}}
\end{array}\right] \\
\sum_{\mathrm{k}=1}^{\mathrm{n}} \mathrm{PF}_{\mathrm{s}, \mathrm{k}}=1 \\
\sum_{\mathrm{k}=1}^{\mathrm{n}} \mathrm{PF}_{\mathrm{b}, \mathrm{k}}=-1
\end{array}
$$
[22].

Eqn.(17) is participation factor in case of $\operatorname{Seller}(s)$ Eqn.(19) is participation factor in case of $\operatorname{Byer}(b)$

The distribution factor is calculated as:-

$\rho_{\mathrm{ij}, \mathrm{s} \rightarrow \mathrm{b}}=\frac{\partial \mathrm{P}_{\mathrm{ij}}}{\partial \mathrm{P}}=\frac{\partial \mathrm{P}_{\mathrm{ij}}}{\partial \delta_{\mathrm{i}}} \frac{\partial \delta_{\mathrm{i}}}{\partial \mathrm{P}}+\frac{\partial \mathrm{P}_{\mathrm{ij}}}{\partial \delta_{\mathrm{j}}} \frac{\partial \delta_{\mathrm{j}}}{\partial \mathrm{P}}+\frac{\partial \mathrm{P}_{\mathrm{ij}}}{\partial \mathrm{V}_{\mathrm{i}}} \frac{\partial \mathrm{V}_{\mathrm{i}}}{\partial \mathrm{P}}+\frac{\partial \mathrm{P}_{\mathrm{ij}}}{\partial \mathrm{V}_{\mathrm{J}}} \frac{\partial \mathrm{V}_{\mathrm{J}}}{\partial \mathrm{P}}$

where the derivatives with respect to the state variables can be determined explicitly from the active and reactive power flow equations and the derivatives with respect to $p$ are determined from the Jacobian inverse matrix. For any state variable the derivative with respect to $p$ is computed as in the following equation:-

$$
\begin{gathered}
\frac{\partial \delta_{i}}{\partial P}=\sum_{k \neq \text { slack }}^{\lambda}\left[P F_{s, k} \frac{\partial \delta_{i}}{\partial P_{k}}\right]+\sum_{k \neq \text { slack }}^{\lambda}\left[P F_{b, k} \frac{\partial \delta_{i}}{\partial P_{\lambda}}\right] \ldots \\
\frac{\partial \delta_{j}}{\partial P}=\sum_{k \neq \text { slack }}^{\lambda}\left[P F_{s, k} \frac{\partial \delta_{j}}{\partial P_{k}}\right]+\sum_{k \neq \text { slack }}^{\lambda}\left[P F_{b, k} \frac{\partial \delta_{j}}{\partial P_{\lambda}}\right] \ldots
\end{gathered}
$$

Eqn. for real power of a short transmission line (i-j) with losses and neglecting shunt admittance is given by:-

$$
P_{i j}=V_{i}^{2} G_{i j}-V_{i} V_{j} Y_{i j} \operatorname{Cos}\left(\delta_{i}-\delta_{j}-\theta_{i j}\right)
$$

Let us consider the system where the lines are loss less. Thus $G_{i j}=0$ and $\theta_{i j}=-90$

The derivatives with respect to the state variables are:-

$$
\begin{gathered}
\frac{\partial \mathrm{P}_{\mathrm{ij}}}{\partial \mathrm{V}_{\mathrm{j}}}=0 \\
\frac{\partial \mathrm{P}_{\mathrm{ij}}}{\partial \mathrm{V}_{\mathrm{i}}}=0 \\
\frac{\partial \mathrm{P}_{\mathrm{ij}}}{\partial \delta_{\mathrm{j}}}=-\mathrm{V}_{\mathrm{i}} \mathrm{V}_{\mathrm{j}} \mathrm{Y}_{\mathrm{ij}} \cos \left(\delta_{\mathrm{i}}-\delta_{\mathrm{j}}\right)
\end{gathered}
$$

\section{POWER FlOw CONTROL WITH TCSC}

Better utilization of existing power system capacities by installing new power electronic controllers such as FACTS has become imperative. FACTS controllers are able to change, in a fast and effective way, the network parameters in order to achieve better system performance. FACTS controllers, such as phase shifter, shunt, or series compensation and the most recent developed converterbased power electronic controllers, make it possible to control circuit impedance, voltage angle, and power flow for optimal operation performance of power systems, facilitate the development of competitive electric energy markets, stimulate the unbundling the power generation from transmission and mandate open access to transmission services, etc. With the practical applications of the converter-based FACTS controllers-STATCOM, SSSC, TCSC and UPFC in power systems, computer modeling of these is of great concern for the planning, operation planning, and control analysis of the FACTS controllers.

Operating Principles of the TCSC:-A simpler TCSC model exploits the concept of a variable series reactance. The series reactance is adjusted automatically, within the limits, to satisfy a specified amount of active power flows through it. The more advanced models use directly the TCSC reactance-firing angle characteristics given in the form of non-linear relation. The TCSC firing angle is chosen to be the state variable in the Newton-Raphson power flow solution.

\section{Equivalent Circuit and Power Flow Constraints of the TCSC}

The TCSC power flow model presented in this section is based on the simple concept of variable series reactance, the value of which is adjusted automatically to constrain the power flow across the branch to a specified value. The amount of reactance is determined efficiently using Newton's method. The changing reactance $X_{t \mathrm{csc}}$, shown in Figure 1, represents the equivalent reactance of all the series connected modules making up TCSC, when operating either in inductive or capacitive regions.

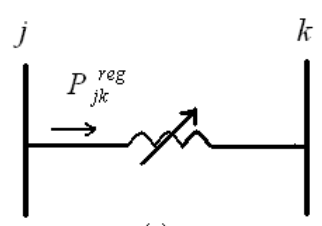

$(a)$

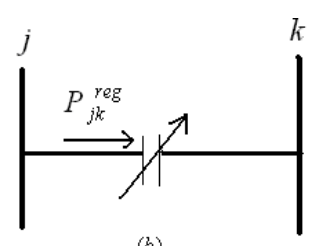

(b)

Fig 1: Thyristor Controlled series compensator equivalent circuit (a) inductive and (b) capacitive operative regions

The transfer admittance matrix of the variable series compensator as shown in Fig. 1 is given by:-

$$
\left[\begin{array}{c}
I_{j} \\
I_{k}
\end{array}\right]=\left[\begin{array}{ll}
j B_{j j} & j B_{j k} \\
j B_{k j} & j B_{k k}
\end{array}\right]\left[\begin{array}{c}
V_{j} \\
V_{k}
\end{array}\right]
$$

For inductive operation we have:-

$$
B_{j j}=B_{k k}=-\frac{1}{X_{t \mathrm{csc}}}
$$




$$
B_{j k}=B_{k j}=\frac{1}{X_{t c s c}}
$$

For capacitive operative regions the signs are reversed. The active and reactive power equations at bus $j$ are:-

$$
\begin{aligned}
& P_{j}=V_{j} V_{k} B_{j k} \sin \left(\theta_{j}-\theta_{k}\right), \\
& Q_{j}=-V_{j}^{2} B_{j j}-V_{j} V_{k} B_{j k} \sin \left(\theta_{j}-\theta_{k}\right),
\end{aligned}
$$

For the Power equations at bus $\mathrm{k}$, the subscripts $\mathrm{j}$ and $\mathrm{k}$ are exchanged in the above equations.

In Newton-Raphson solutions these equations are linearized with respect to the series reactance. For the conditions shown in Fig 1, where the series reactance regulates the amount of active power flowing from bus $\mathrm{j}$ to $\mathrm{k}$ at a value ${ }^{\text {reg }}{ }^{k}$, the set of linearized power flow equations can be expressed as mentioned below:-

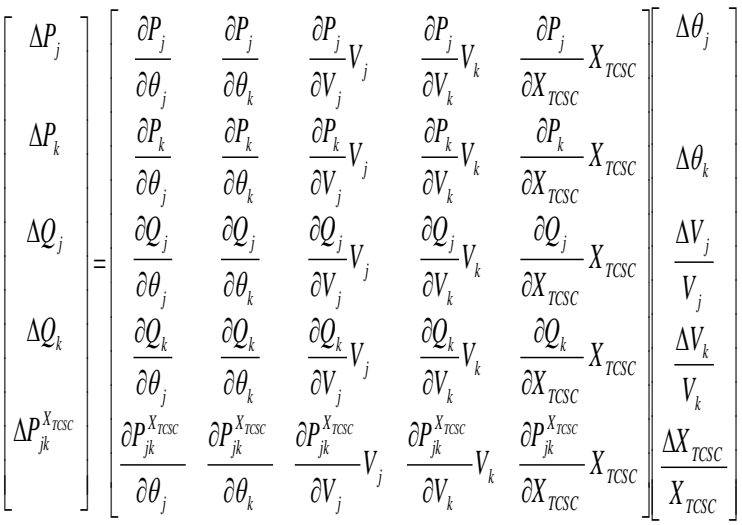

$$
\begin{aligned}
& \Delta P_{j k}^{X_{\text {TCSC }}}=P_{j k}^{r e g}-P_{j k}^{X_{\text {TCSC, cal }}}
\end{aligned}
$$

is the active power flow mismatch for the series reactance; given by

$$
\Delta X_{T C S C}=X_{T C S C}^{i}-X_{T C S C}^{(i-1)}
$$

Is the incremental change in series reactance; and $P_{j k}^{X_{\text {TCSC, cal }}}$ is calculated power as given by equation (29). The Jacobian elements for the series reactance are given below:-

$$
\begin{aligned}
& \frac{\partial P_{j}}{\partial X_{T C S C}} X_{T C S C}=-V_{j} V_{k} B_{j k} \sin \left(\theta_{j}-\theta_{k}\right), \\
& \frac{\partial Q_{j}}{\partial X_{T C S C}} X_{T C S C}=V_{j}^{2} B_{j j}+V_{j} V_{k} B_{j k} \sin \left(\theta_{j}-\theta_{k}\right), \\
& \frac{\partial P_{j k}}{\partial X_{T C S C}} X_{T C S C}=\frac{\partial P_{j}}{\partial X_{T C S C}} X_{T C S C},
\end{aligned}
$$

The state variable $X_{\text {TCSC }}$ of the series controller is updated at the end of each iteration step according to:-

$$
\Delta X_{T C S C}^{(i)}=X_{T C S C}^{(i-1)}+\left(\frac{\Delta X_{T C S C}}{X_{T C S C}}\right)^{(i)} X_{T C S C}^{(i-1)}
$$

Discussion of 3-Bus Results
Consider the three-bus, three line system, the line reactance are $0.9,0.37$, and 0.28 p. u., and the line MVA ratings are 1.0, 1.3, and 1.4 p. u., for lines $1-2,1-3$, and $2-3$, respectively. The initial operating point shown is set up with voltages equal to 1.0, 1.0, and 1.04p.u.for buses 1,2, and 3 . Reactive power generation at every bus is unlimited.

Transactions between areas 1 to 2,1 to 3 , and 2 to 3 (seller/buyer) were simulated across this system. ATC was computed by three methods [1].

Sequential full AC power flow, i.e. the actual ATC;

B.) Linear ATC, as described in Section II-A;

C.) Linear ATC with reactive power flows,

The results are shown in per unit $\left(S_{\text {base }}=100 \mathrm{MVA}\right)$ in Table 1. Corresponding errors are computed for methods B and $\mathrm{C}$ with respect to the actual ATC values.

TABLE 1 ATC Results For THE THREE -Bus System

\begin{tabular}{|l|l|l|l|}
\hline $\begin{array}{l}\text { Transfer } \\
\text { Direction }\end{array}$ & Fr 1 To 2 & Fr 1 To 3 & Fr 2 To 3 \\
\hline Limiting line & $3-1$ & $3-1$ & $3-2$ \\
\hline$S_{j k}^{\max }$ & 1.3 & 1.3 & 1.4 \\
\hline$P_{j k}^{*}$ & 1.237 & 1.237 & 1.342 \\
\hline$\rho_{j k, i}$ & -0.5902 & -0.7667 & -0.8235 \\
\hline Actual $\Delta P_{s}^{j k}$ & 2.030 & 1.63 & 1.63 \\
\hline Linear $\Delta P_{s}^{j k}$ & 2.203 & 1.696 & 1.700 \\
\hline $\begin{array}{l}\text { Reactive } \\
\Delta P_{s}^{j k}\end{array}$ & 2.096 & 1.614 & 1.629 \\
\hline
\end{tabular}

The line data include the line MVA rating $S_{j k}^{\max }$, the maximum active flow $P_{j k}^{*}$, and the linearized distribution factors computed from the initial ac power flow solution. The results are organized by transfer between areas $1-2,1-3$, and 2-3. For each direction, the transfer values $\Delta P_{s}^{j k}$ that overload the limiting line in the system are shown. For the transfer from area 1 (seller) to area 2 (buyer), the limiting element is line 3-1 (line end 3), which reaches its thermal limit with a transfer of 2.03 p. u, or $203 \mathrm{MW}$. This is the exact ATC value for this particular transfer.

For the transfer from area 1 (seller) to area 3 (buyer), the limiting element is again line 3-1 (line end 3), which reaches its thermal limit with a transfer of 1.63 p. u., or $163 \mathrm{MW}$. This is the exact ATC value for this particular transfer.

For the transfer from area 2 (seller) to area 3 (buyer), the limiting element is line 3-2 (line end 3), which reaches its thermal limit with a transfer of 1.63 p. u., or $163 \mathrm{MW}$. This is the exact ATC value for this particular transfer [1].

\section{Simulation of a 30-Bus system}

The simulation has been now carried out to obtain the results for IEEE 30-bus system by incorporating the FACTS device (i.e. TCSC), in addition to results obtained for IEEE3 bus system as depicted in table no.1. The TCSC is located in the line connected between 10th bus and 22nd bus. The 
real and reactive power settings of the TCSC are $40 \mathrm{MW}$ and 2 MVAR. The ATC enhancement results for the 30-bus system with TCSC can be observed in Table 2.

TABLE 2: ATC RESUltS FOR THE 30-BUS SySTEM

\begin{tabular}{|c|c|c|c|c|c|c|c|}
\hline \multirow{2}{*}{$\begin{array}{l}\text { Transfer } \\
\text { Direction }\end{array}$} & \multirow[b]{2}{*}{$\begin{array}{l}\text { Limitin } \\
\text { g Line }\end{array}$} & \multicolumn{2}{|c|}{ PTDF } & \multicolumn{2}{|c|}{$\begin{array}{l}\text { Without TCSC } \\
\text { (p.u) }\end{array}$} & \multicolumn{2}{|c|}{ With TCSC （p.u) } \\
\hline & & $\begin{array}{l}\text { With- } \\
\text { Out } \\
\text { TCSC }\end{array}$ & $\begin{array}{l}\text { With } \\
\text { TCSC }\end{array}$ & $\begin{array}{l}\Delta \mathrm{P}_{\mathrm{i}} \\
\text { j(Linear) }\end{array}$ & $\begin{array}{l}\Delta \mathrm{P}_{\mathrm{ij}} \\
\text { (Reactive) }\end{array}$ & $\begin{array}{c}\Delta \mathrm{P}_{\mathrm{ij}} \\
\text { (Linear) }\end{array}$ & $\begin{array}{l}\Delta P_{i j} \\
\text { (Reactive) }\end{array}$ \\
\hline $2-5$ & $1-2$ & 0.0549 & 0.0579 & 2.5688 & 1.4903 & 1.2371 & 0.8651 \\
\hline $2-6$ & $1-3$ & -0.1856 & 0.1600 & 3.5677 & 1.9730 & 1.8167 & 0.8716 \\
\hline $1-2$ & $2-4$ & 0.0815 & 0.0810 & 13.9719 & 8.1926 & 11.5362 & 8.1240 \\
\hline $6-28$ & $5-7$ & 0.0281 & 0.0413 & 2.5710 & 2.4160 & 2.5662 & 1.6808 \\
\hline $7-6$ & $6-7$ & 0.8210 & -0.8321 & 1.8452 & 1.5483 & 1.2300 & 0.9203 \\
\hline 18- 19 & $6-8$ & -0.1200 & 0.1000 & 9.1325 & 4.5898 & 7.6627 & 3.2019 \\
\hline $29-30$ & $9-10$ & -0.1514 & 0.1873 & 10.1563 & 4.9135 & 6.9346 & 2.8590 \\
\hline $6-7$ & $12-14$ & 0.4413 & 0.4974 & 2.5254 & 1.2103 & 2.0104 & 1.0391 \\
\hline $10-21$ & $12-16$ & 0.0230 & 0.0154 & 6.4761 & 3.1294 & 4.6283 & 2.1357 \\
\hline 23- 24 & 14- 15 & 0.0383 & 0.0287 & 3.8264 & 1.8121 & 2.8561 & 0.9861 \\
\hline 24- 22 & |18-19 & -0.0639 & -0.0694 & 2.1648 & 1.8248 & 1.7201 & 1.4457 \\
\hline $28-8$ & 19-20 & -0.0761 & -0.0811 & 1.5915 & 0.4553 & 1.1895 & 0.3963 \\
\hline $5-7$ & $10-17$ & 0.0216 & 0.0233 & 2.9647 & 1.6937 & 2.4719 & 1.4238 \\
\hline $25-27$ & 21-22 & 0.0725 & 0.1005 & 1.7983 & 1.3856 & 1.2576 & 1.1462 \\
\hline $2-6$ & $25-26$ & 0.1321 & 0.1351 & 1.2996 & 1.2996 & 1.6074 & 1.2383 \\
\hline 27- 29 & 29-30 & 0.2530 & 0.2821 & 3.8805 & 1.9396 & 3.5451 & 1.1857 \\
\hline $19-20$ & $8-28$ & 0.2545 & 0.2587 & 4.1235 & 2.1601 & 4.0964 & 1.9177 \\
\hline $5-7$ & $\begin{array}{l}6- \\
28\end{array}$ & 0.0011 & 0.0011 & 1.7414 & 1.4232 & 1.6158 & 1.1591 \\
\hline $3-4$ & $\begin{array}{c}27- \\
28\end{array}$ & -0.0035 & -0.0041 & 1.9205 & 1.3354 & 1.8674 & 0.9279 \\
\hline
\end{tabular}

\section{CONCLUSION}

A method of calculating ATC by incorporating reactive power flows with FACTS device i.e. TCSC is proposed in this paper. From the inspection of Table-2, it is inferred that the use of FACTS device, particularly the TCSC, enhances the ATC substantially. Therefore, it is concluded that FACTS technology can offer an effective and promising solution to boost the usable power-transfer capability, thereby improving transmission services of the present market-based power systems. Furthermore, the results obtained for IEEE-30 bus system in this work show that the inclusion of reactive power and FACTs device in a linear ATC can enhance the maximum transaction over a transmission system.

\section{REFERENCES}

[1] S. Grijalva W. Sauer, J. D. Weber, "Enhancement of Linear ATC Calculations by the Incorporation of Reactive Power Flows", IEEE Transactions on Power Systems, Vol. 18, No. 2, pp.619-624, May 2003.

[2] “Available Transfer Capability Definitions and Determination", North American Electric Reliability Council, Reference Document, June 1996. Source: www.westgov.org/wieb/wind/06-96NERC atc.pdf.

[3] H.D. Chiang, A.J.Flueck, K.S. Shah and N.Balu, "CPFLOW: A Practical Tool for Tracing Power System Steady State Stationary Behavior due to Load and Generation Variation", IEEE Transactions on Power Systems, Vol. 10, pp.623-634, May 1995.

[4] G.C. Ejebe, J.Tong, G.C.Waight, J.G. Frame, X. Wang and W.F.Tenney, "Available Transfer Capablity Calculations", IEEE Transactions on Power systems, Vol. 113,No. 4, pp.1521-1527, November 1998

[5] M.H. Gravener, C. Nwankpa and T.S. Yeoh, "ATC Computational Issues", Proceedings of 32nd Hawaii International Conference on System Sciences, pp. 1-6., January 1999.

[6] R. Wang, R.H. Lassester, J.Meng and F.L. Alvarado, "Fast Determination of Simultaneous Available Transfer Capability (ATC)", Power System Engineering Research Centre (PSERC) Publications, 1999 (http://www.pserc.wisc.edu).

[7] G. C. Ejebe, J. G. Waight, M. Santos-Nieto, and W. F. Tinney, "Fast Calculation of Linear Available Transfer Capability", IEEE Transactions on Power Systems, Vol. 15, pp. 1112-1116, Aug. 2000.

[8] A. Kumar, S.C. Srivastava, S. N. Singh, "Available Transfer Capability (ATC) Determination in a Competitive Electricity Market using A.C. Distribution Factors", Electric Power Components and Systems Journal, Vol. 32, No. 9, pp. 927-939, September 2004.

[9] J.C.O. Mello, A.C.G. Mello and S. Granveille, "Simultaneous Available Transfer Capability Assessment by Combining Interior Point Methods and Monte Carlo Simulation", IEEE Transactions on Power Systems, Vol.12, No. 2, pp.736-742., May 1997.

[10] G. Hamoud, "Assessment of Available Transfer Capability of Transmission Systems", IEEE Transactions on Power systems, Vol.15, No. 1, pp.27-32., February 2000.

[11] C. Luonan, A. Ono, Y. Tada, H. Okamoto and R. Tanabe, "Optimal Power Flow Constraints by Transient Stability", Proceedings of International Conference on Power System Technology(Power Con.), Vol.1, pp.1-6, December 2000.

[12] M.Ilic,Y.T. Yoon and Zobian, "Available Transmission Capacity (ATC) and its Value under Open Access", IEEE Transactions on Power Systems", Vol.12, No. 2, pp.636-645 May 1997.

[13] P.W. Sauer, "Technical Challenges of Computing Available Transfer Capability (ATC) in Electric Power Systems", Proceedings of 30th Hawaii International Conference on System Sciences, Vol.5, pp.589-593, January 1997.

[14] N.G. Hingorani and L.Gyugi, 'Understanding FACTS, Concepts and Technology of Flexible AC Transmission Systems', (IEEE Press 2001).

[15] Y. Xiao, Y.H. Song, C.C. Liu and Y.Z. Sun, "Available Transfer Capability Enhancement using FACTS Devices", IEEE Transactions on Power systems, Vol.18, No.12, pp.305-312, February 2003.

[16] A. Kazemi and B. Badrzadeh, "Modelling and Simulation of SVC and TCSC to Study their Limits on Maximum Load ability point", International Journal of Electrical Power and Energy Systems, Vol.26, Issue 5, pp. 381-388, June 2004.

[17] M. Rashidinejade, H. Frahmand, M.F Firuzabad and A.A. Gharaveisi, "ATC Enhancement using TCSC via Artificial Intelligent 
Techniques", Electric Power System Research, Vol. 78, pp. 11-20. Issue 1, 2008.

[18] C.A. Canizares, A. Berizzi and P. Marannino, "Using FACTS Controllers to Maximize Available Transfer Capability", Proceedings of Bulk Power Systems Dynamics And Control IVRestructuring, Santoroni, Greece, pp.633- 641, August 1998.

[19] R.Srinu Naik, K.Vaisakh, K.Anand Kumar, N. K. Yadav, Ibraheem, "ATC Enhancement with TCSC using Linear and Reactive Methods", IJEEE-Journal, Vol .03, No.04, pp.12-22, Summer Edition-2009.

[20] N.K. Yadav, Ibraheem, K.Anand Kumar, R. Srinu Naik, K.Vaisakh, "Identification of Overloading Line Using Linear and Reactive ATC Methods with PTDF", IJEEE-Journal, pp. 86-96,Vol. 04, N0.06, Summer Edition-2009.

[21] S.Grijalva, Peter W. Sauer, "Reactive Power Considerations in Linear ATC Computation”, Decision Support Systems, Volume 30, Issue 3, pp. 327-340, January 2001.

[22] S. Grijalva, "Complex Flow-Based Non-Linear ATC Screening", Ph.D. dissertation, Univ. of Illinois at Urbana- Champaign, Urbana, 2002.

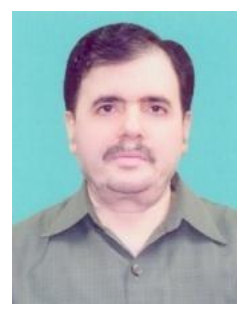

Ibraheem received the B.Sc. Engg. (Hons.), M.Sc. Engg., and Ph.D. degrees in electrical engineering from Aligarh Muslim University, Aligarh, India, in 1982, 1987 and 2000, respectively.

He worked with Delhi Development Authority (Slum Wing) at Delhi, India. Since January 1998 he has been with the Department of Electrical Engineering, Faculty of Engineering and Technology, Jamia Millia Islamia (Central University), New Delhi, India, where he is currently Professor of Electrical Engineering. He had been Head of the Department of Electrical Engineering since 2002 to 2005. His current activities include teaching and research in the areas of power system control, optimal control theory, sub- optimal control of power systems, applications of soft computing techniques in power systems, and HVDC transmission systems.

Professor Ibraheem is a member of various academic societies of national and international repute. He has participated in and presented papers at many national and international seminars/ conferences/ workshops. He has published a number of research papers in national/international journals and is continuously engaged in guiding research activities at graduate, postgraduate and doctoral levels. In 1998 he was the recipient of the Gold Medal from the Union Ministry of Power and Energy, India, for one of his published research articles.

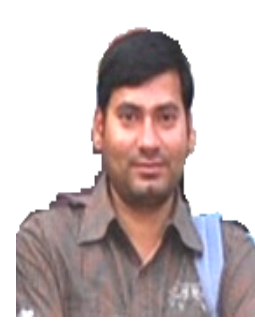

Naresh Kumar Yadav obtained B.Tech. in electrical engineering from Maharshi Dayanand University, Rohtak (Haryana), India and M.Tech. in electrical engineering from National Institute of Technology, Kurukshetra, India, in 2000 and 2004, respectively.

He worked with Imperial Malts Ltd., Gurgaon, India from 2000 to 2002. From 2004 to 2006 he worked with Apeejay College of Engineering, Sohna (Gurgaon), India. Since August-2006 he has been with Department of Electrical Engineering, Faculty of Engineering and Technology, DeenBandhu Chhotu Ram University of Science \& Technology, Murthal (Sonepat)-Haryana, India, where he is currently Assistant Professor. Presently he is pursuing his Ph.D. research at Jamia Millia Islamia (Central University), New Delhi-110025. His research interests include power system deregulation, FACTS applications to power system restructuring, Automatic Generation Control etc.

Mr. Yadav is a life time member of Indian Society for Technical Education. $\mathrm{He}$ has participated in and presented papers at three national and three international conferences. He has published four research papers in international journals. 